\title{
Arbor
}

\section{La música por excelencia. La Fundación Albéniz: una iniciativa pionera en nuestro país}

\section{Paloma O'Shea}

Arbor CLXVIII, 663 (Marzo 2001), 395-405 pp.

\section{Los comienzos...}

Mi experiencia como alumna de piano en Bilbao y en Francia, y mi conocimiento del mundo de la música en nuestro país, me llevaron a intervenir - hace ya algunos años- en el terreno de la promoción musical. Mi objetivo principal se centró en facilitar a los jóvenes instrumentistas españoles su entrada en los entonces alejados escenarios internacionales. Gracias a la ayuda de unos pocos pero entusiastas colaboradores fundé el Concurso Internacional de Piano de Santander: mi primera meta en lo que sería luego un largo y maravilloso camino. Aquellos años fueron de enorme trabajo y entusiasmo, sin oficinas ni cuadros administrativos, sacando adelante el Concurso casi familiarmente; si había que fotocopiar, fotocopiaba, si había que escribir a máquina, escribía... Cuando concluía una convocatoria nos parecía milagroso.

Con el paso de los años el Concurso fue ganando prestigio internacional y conseguimos formar una pequeña administración que terminó de dar la necesaria estabilidad al proyecto. Pero esta consolidación coincidió también con una cierta decepción por mi parte. Yo lo había creado fundamentalmente para promocionar a jóvenes españoles, pero éstos no lograban llegar a las fases finales. Entendí entonces que el problema no residía en la promoción sino en la educación, en las dificultades que encontraba la enseñanza oficial para formar instrumentistas de excelencia. Soy consciente de que la administración pública invierte mucho dinero en la enseñanza musical y de que se cuenta con muy buenos profesores, pero el hecho estaba ahí, a la vis- 


\section{Paloma O'Shea}

ta de todos, y el Concurso tampoco resultaba un instrumento útil para solucionarlo.

Con la colaboración de Federico Sopeña y Enrique Franco puse en marcha un segundo programa: las «master classes» o clases magistrales de instrumento, que comenzaron a celebrarse en Santander los años que no había Concurso. La Universidad Internacional Menéndez Pelayo las acogió entre sus cursos y las integró en su oferta veraniega. Fuimos trayendo, año tras año, con renovada ilusión, a distintas personalidades del panorama internacional de la educación musical para que entraran en contacto con nuestros maestros y estudiantes, facilitando así la recepción de nuevas metodologías. La experiencia resultó muy positiva y me empujó a dar el paso definitivo. Si el problema residía en la falta de una formación adecuada para músicos de máximo nivel, había que dotar a nuestro país de un centro capaz de lograrlo.

Para desarrollar los nuevos proyectos que me iba planteando necesitaba de un marco jurídico y empresarial apropiado, con la idea siempre en mente de intentar aportar a la sociedad algo que necesitaba, de contribuir modestamente a la modernización de mi país en un terreno muy concreto. Así creamos en 1986 la Fundación Albéniz, sin patrimonio alguno, pero con una clara vocación musical. La Infanta Dña. Margarita aceptó la Presidencia de Honor y Federico Sopeña la Vicepresidencia.

El siguiente paso consistió en dar sentido a la recién nacida fundación, ordenando de algún modo las ideas que teníamos de un proyecto que nadie había intentado todavía en España. Era necesario, por tanto, avanzar en la organización de la casa, definir claramente las prioridades, las líneas de acción y el sistema de financiación. Con un director general al frente, la fundación vio crecer su número de empleados y conseguimos afianzar una mentalidad necesaria para garantizar la continuidad de la labor emprendida. Hicimos estudios de viabilidad, seleccionamos proyectos y empezamos a vislumbrar lo que podría llegar a ser aquel proyecto en un futuro no muy lejano. Decidimos entonces establecer cuatro líneas básicas de actuación, la divulgación, la docencia, la investigación y la creación, que marcarían -y siguen marcando actualmente - la táctica y la estrategia de la Fundación Albéniz.

\section{Cuatro líneas básicas}

La Divulgación es la más antigua de nuestras líneas de acción y el Concurso de Piano de Santander su principal programa. Venimos realizándolo desde 1972 con la satisfacción de haber ayudado a espléndidos jóvenes pianistas a promocionarse. Pero el Concurso es algo más que unos 
cuantos días de frenética actividad en el delicioso verano santanderino. Cuando finaliza, aunque mejor habría que decir cuando aparentemente finaliza, comienza otra fase quizás aún más exigente. Para organizar los conciertos y grabaciones de los premiados nuestro equipo técnico tiene que programar y seguir la ejecución de conciertos por todo el mundo, además de realizar, editar y distribuir sus grabaciones: una actividad mucho más discreta, pero posiblemente también más importante.

Además del Concurso, la Fundación organiza conciertos como resultado de su intensa actividad musical por toda la geografía española. Actualmente organizamos más de doscientos conciertos anuales y hemos conseguido formar decenas de agrupaciones estables de música de cámara.

La Fundación ha impulsado también diversas exposiciones, como las dedicadas a Rubinstein, Mompou o Albéniz y ha organizado distintos homenajes, como el que en el año 1999 quisimos dedicar a Federico Sopeña, tan ligado, como ya he dicho antes, a la propia historia de la fundación. Fruto de ese homenaje es el libro «Federico Sopeña y la España de su tiempo: 1939-1991», que ha tenido una entusiasta acogida por parte de la crítica especializada.

Otra manifestación importante de esta línea de divulgación es la creación del Premio «Yehudi Menuhin a la Integración de las Artes y la Educación» que otorga la Fundación desde 1999. Con él pretendemos reconocer y premiar la labor que desempeñan muchos profesores-artistas en el terreno de la formación musical en cualquier rincón del planeta; de tantos maestros completos que sobresalen en el ejercicio de las dos vertientes de su maestría: el arte y la educación.

En su primera edición, el galardonado fue Alfredo Kraus, que dejó una estela de generoso trabajo y de extraordinaria calidad humana en todos los lugares en que ejerció su magisterio. Y en la edición de este año el premio ha sido para el maestro Piero Farulli, uno de los más genuinos representantes de una estirpe de artistas y humanistas que hunde sus raíces en los tiempos del Renacimiento italiano.

La Docencia es actualmente la línea más importante, a la que dedicamos nuestros principales esfuerzos y la que satisface de un modo más pleno mi deseo de formar a los jóvenes músicos. Durante años estudié los centros de formación de excelencia más importantes de Europa, Rusia y Estados Unidos, deteniéndome en sus aspectos metodológicos. Con la colaboración de British Petroleum-Petromed, la Fundación convocó en Madrid a una selección de destacados expertos mundiales en pedagogía musical, para que dieran forma sobre el papel al ideal de Escuela que nosotros teníamos en mente. Sólo entonces, cuando tuvimos claro el mo- 
delo pedagógico a seguir, nos lanzamos a una aventura que, afortunadamente, es hoy una realidad llena de futuro.

Con la puesta en marcha en 1991 de la Escuela Superior de Música Reina Sofía, nuestro país comenzó a disponer de un centro de alta formación musical. La Escuela quedó abierta a jóvenes de todo el mundo, pero tuvo desde su nacimiento un compromiso especial con los músicos españoles y,

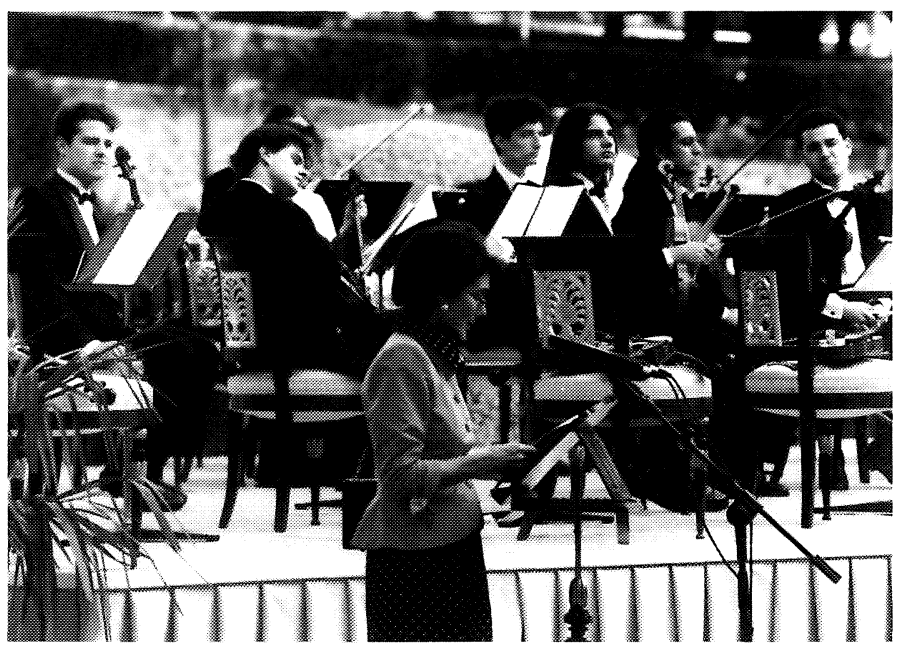

Discurso de Doña Paloma O'Shea en el Palacio de la Granja de San Ildefonso en el acto de clausura de un curso académico de la Escuela Superior de Música Reina Sofía. en general, con los jóvenes del área latinoamericana.

La solidez del modelo educativo, la solvencia de los asesores que nos han ayudado a seleccionar el profesorado - entre los que quisiera destacar a Mstislav Rostropovich, Zubin Mehta y Alicia de Larrocha- y el prestigio internacional de nuestros profesores titulares de instrumento, han despertado la atención y el interés de muchos. Y me gustaría aprovechar estas líneas para reiterar de nuevo, en mi nombre, en el de los patronos y en el de todo el equipo humano de la Fundación, la entusiasta colaboración de Su Majestad la Reina. Cuando la Escuela era sólo un proyecto respaldado por unas pocas personas, Su Majestad aceptó ofrecer su nombre para la Escuela, así como la Presidencia de Honor. Era una prueba de confianza de la corona en una empresa privada que apenas había podido demostrar nada más allá de su voluntad.

No resulta difícil entender la importancia que este hecho tuvo a la hora de crear expectativas en los foros internacionales. El prestigio de nuestra Reina en los medios culturales e intelectuales de todo el mundo es extraordinario, por lo que su aval nos fue de gran ayuda. Para el equipo humano que día a día trabaja en este importante reto, el gesto supuso - y continúa suponiendo - una seria llamada de atención a la responsabilidad; si la Reina apostaba por un proyecto de modernización musical como el nuestro no podíamos permitirnos el lujo de ningún desmayo. 
La música por excelencia. La Fundación Albéniz: una...

La clave de nuestra pedagogía es la relación humana. Por eso cada profesor tiene un número reducido de alumnos — nunca más de nueve, con los que convive intensamente y con los que comparte casa, comedor y ratos de ocio. Este permanente contacto garantiza que el seguimiento de su aprendizaje resulte óptimo. La masificación está reñida con la calidad, de modo que si queremos buenos músicos debemos proporcionar a los jóvenes un ambiente de tranquilidad, retiro y concentración. De otra manera es imposible. En realidad no hemos hecho otra cosa que redescubrir la escuela occidental clásica - que nace en los conventos en torno al siglo XIII- de la mano de la literatura reformista de principios del siglo XX.

Desde 1991 la Escuela ha estado situada provisionalmente en Pozuelo de Alarcón, en una zona ajardinada en las afueras de Madrid, lejos del bullicio y la tensión de una gran ciudad. Pero ya hace tiempo que las instalaciones se han quedado pequeñas para las necesidades de un centro educativo que cada curso crece cuantitativa y cualitativamente. Por eso es tan importante el proyecto - ya en marcha- de la nueva sede diseñada por el arquitecto Miguel de Oriol: un edificio moderno y funcional que se levantará en uno de los lugares más representativos del pasado histórico de Madrid, junto al Palacio Real y el Teatro Real.

El nuevo edificio contará con un auditorio en comunicación directa con la calle y capacidad para cerca de quinientos espectadores. Además

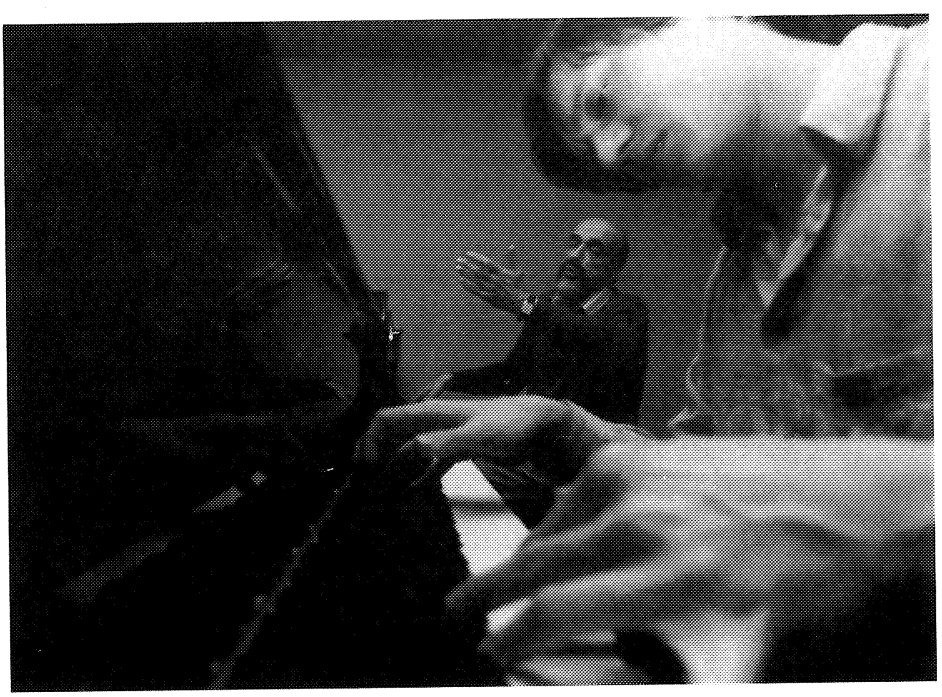

Stanislav Judenitch, antiguo alumno de la Escuela, recibiendo los consejos de Dimitri Bashkirov, Titular de la Cátedra de Piano de la Escuela. de las zonas destinadas a la administración, la Escuela se completará con un gran comedor, aulas de instrumento, cabinas de ensayo, un laboratorio de sonido equipado con los sistemas más modernos, un amplio Centro de Archivo y Documentación y una magnífica biblioteca. 


\section{Paloma O'Shea}

De esta manera, la Escuela desarrollará sus actividades en un barrio lleno de resonancias culturales, no sólo por la cercanía de otros focos de cultura, sino porque en él han vivido grandes músicos que serán siempre una referencia para un centro dedicado a la formación de jóvenes músicos.

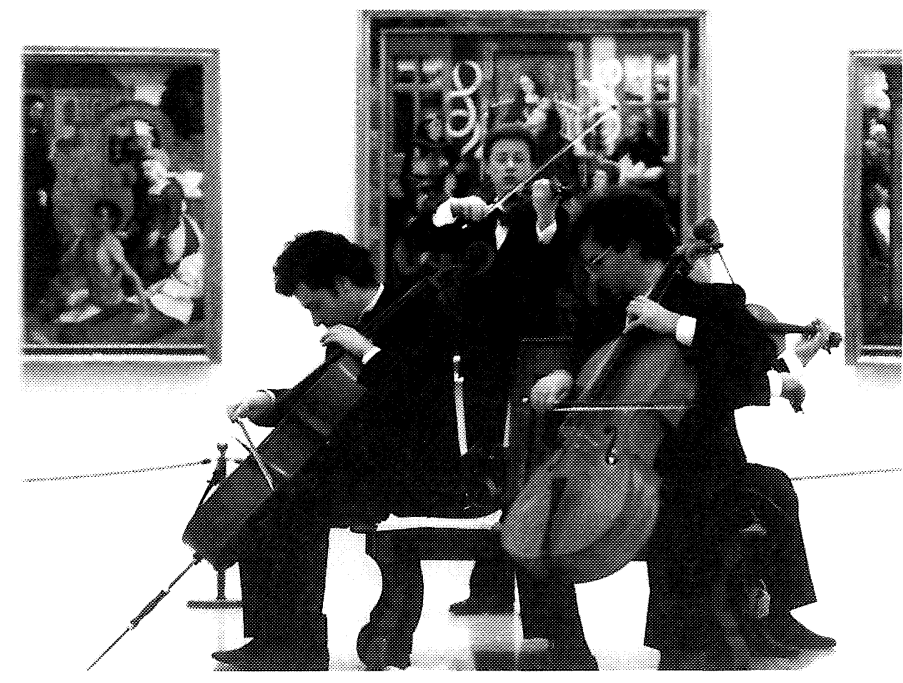

Ensayo de un grupo de cámara de la Escuela, minutos antes de actuar el Museo del Prado.

La investigación, otra de nuestras líneas básicas de actuación, surgió de modo natural, como una contribución al conocimiento de la música española. Hablando con algunos profesionales, una tiene la sensación de que la música es un arte aislado, algo encerrado en sí mismo, sin conexión con otros mundos de la cultura. Hasta el punto de que una de las características menos ejemplares del medio musical español es su distanciamiento de las restantes disciplinas artísticas y humanísticas. No hay suficiente conciencia de la relación entre la música, la pintura, la poesía, la arquitectura o la literatura; una idea que expresa bellísimamente José Hierro cuando dice que «todas las artes se intercomunican, abren sus ventanas a las demás musas, aspiran a ser sólo una».

No debe olvidarse que, en cada momento, hay un conjunto de ideas y tendencias que marcan a todos los creadores y unifican su estilo. Así, cuando hablamos de romanticismo estamos haciendo referencia a algo que pone en relación a Beethoven con Goya, a Schumann con Becquer, o a Turner con Brahms. Por eso, la Fundación ha prestado especial atención a que en la Escuela los alumnos reciban una sólida formación artística y humanística, que se refleja en su Programa de Estudios con asignaturas de Historia del Arte o Estética, entre otras.

Esta línea de investigación tiene su principal referencia en el Centro de Archivos y Documentación Albéniz, que ha nacido con la vocación de preservar el frágil patrimonio histórico en papel. El archivo histórico reúne fondos documentales en los que la música aparece como centro vertebra- 
dor, de manera que se cumpla ese objetivo fundamental de unir la música con otras disciplinas artísticas e intelectuales.

En junio de este mismo año tuvimos el honor de hacer la presentación oficial de nuestro Centro de Archivos. Fue en el hotel Ritz, ante numerosos medios de prensa y personalidades del mundo de la política, la empresa y la cultura.

Casi todos los fondos que contiene el archivo corresponden a donaciones hechas por figuras destacadas del mundo de la música o a trabajos desarrollados por la propia Fundación. Toda la documentación ha sido tratada con el máximo rigor de la técnica documentalista $\mathrm{y}$ ya se encuentra a disposición de la comunidad científica y de todas aquellas personas interesadas en los distintos aspectos que abarca el mundo de la música y la cultura. Los fondos más

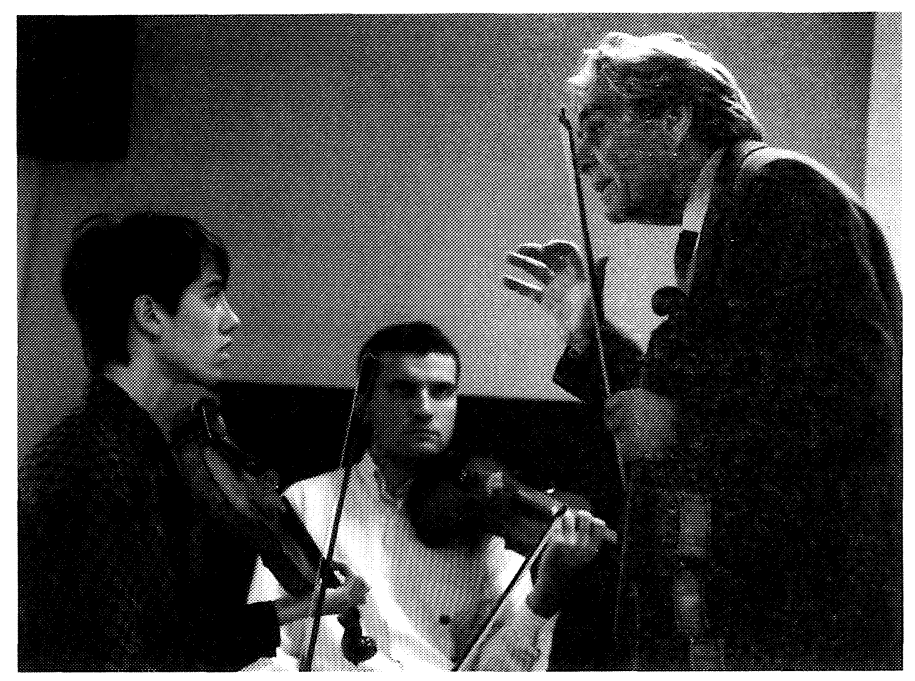

Una instantánea del maestro Piero Farulli en clase. importantes de los que disponemos hasta ahora son los de Isaac Albéniz, Arturo Rubinstein, Federico Mompou, Luis Galve y Vicente Cacho.

La creación es para la Fundación Albéniz sinónimo de renovación e iniciativa. La Fundación muestra así su apoyo a la creación musical encargando periódicamente piezas originales a compositores españoles y comprometiéndose a su posterior estreno. De esta forma se promueve un fondo de obras españolas contemporáneas, al tiempo que se ayuda e incentiva la creación nacional.

Artistas como Cristóbal Halffter o Gonzalo de Olavide han escrito alguna de las obras obligadas en varias ediciones del Concurso Internacional de Piano de Santander, mientras que las exposiciones de Rubinstein y Albéniz sirvieron, por otra parte, para encargar música a más de una veintena de autores. Otros cuatro músicos, Montsalvatge, De Pablo, Durán Loriga y Charles compusieron obras en homenaje a Isaac Albéniz. 
Pero este espíritu creativo va más allá y la Fundación también se ha marcado el objetivo de llevar la cultura al mundo virtual e instalarla con pleno derecho. Para ello puso en marcha hace trece años una empresa -Ifigenia-, que actualmente es propiedad en su totalidad de Terra y que aúna dos facetas primordiales: servicio y modernidad. Sobre estas dos características se asientan sus actividades de investigación y de desarrollo en el ámbito de la educación musical y en la utilidad de las nuevas tecnologías al servicio de la sociedad.

Mediante esta iniciativa se pretende desarrollar un innovador software educativo para el aprendizaje y la formación musical, que incorporará las más modernas técnicas de audio, video y tratamiento de la información digital. Sin duda, la creación de un portal de estas características es un pro-

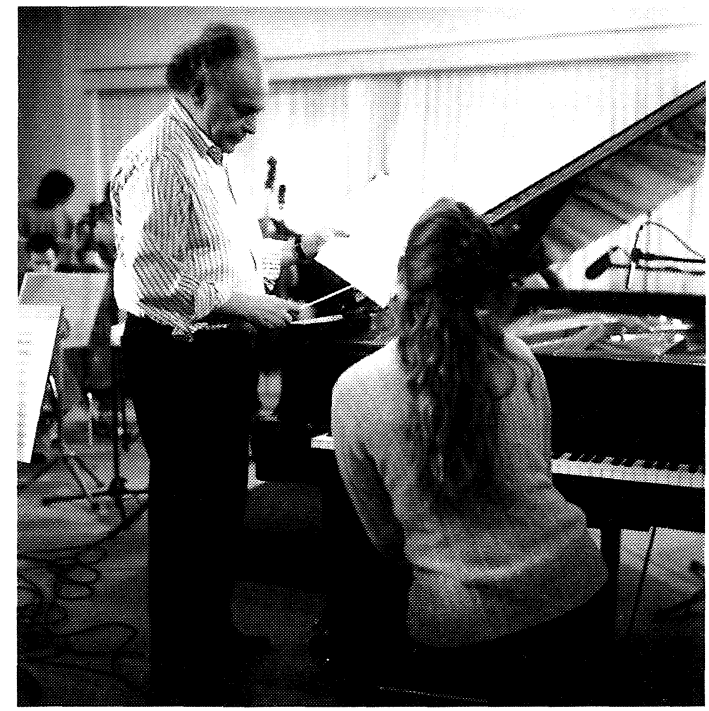

Lecciones Magistrales de Lorin Maazel en la Escuela. yecto totalmente pionero en nuestro país que permitirá rentabilizar socialmente la riqueza de los contenidos y la experiencia que posee la Fundación Albéniz en la formación musical de máximo nivel.

\section{La financiación de una empresa cultural}

He procurado explicar en síntesis la historia, la organización y las principales actividades organizadas por la Fundación Albéniz. Como se puede observar las tareas son ambiciosas y comprometidas, pero también resultan caras. No hay que olvidar que hoy ya son más de 160 personas las que trabajan por cuenta propia o ajena con nosotros. Como ya adelanté al comienzo de estas páginas la Fundación carecía en su inicio de patrimonio financiero, así que imagino que más de algún lector se estará preguntando de dónde sacamos el dinero para sufragar los muchos gastos que generan todos estos programas.

Tradicionalmente se ha considerado que la cultura era un pozo sin fondo, una actividad altruista pero, en ningún caso, una inversión. He 
La música por excelencia. La Fundación Albéniz: una...

escuchado en numerosas ocasiones, y de labios de personas que ocupan posiciones relevantes en el mundo económico, que el compromiso social de la empresa comienza y termina en el logro de beneficios, siendo una empresa eficaz, haciendo bien su trabajo. Esta afirmación siempre me ha sorprendido porque una empresa siempre está inscrita en un determinado marco social, y del desarrollo de ese marco depende su crecimiento y muchas veces su propia razón de ser.

No podemos vivir ajenos a los acontecimientos que se producen a nuestro alrededor, sean políticos, sociales o culturales. La sociedad es una empresa que a todos incumbe, porque de ella todos somos accionistas. Además, detrás de esa afirmación pesimista, se esconde un prejuicio inaceptable y erróneo: la creencia de que invertir en cultura no es rentable en términos puramente

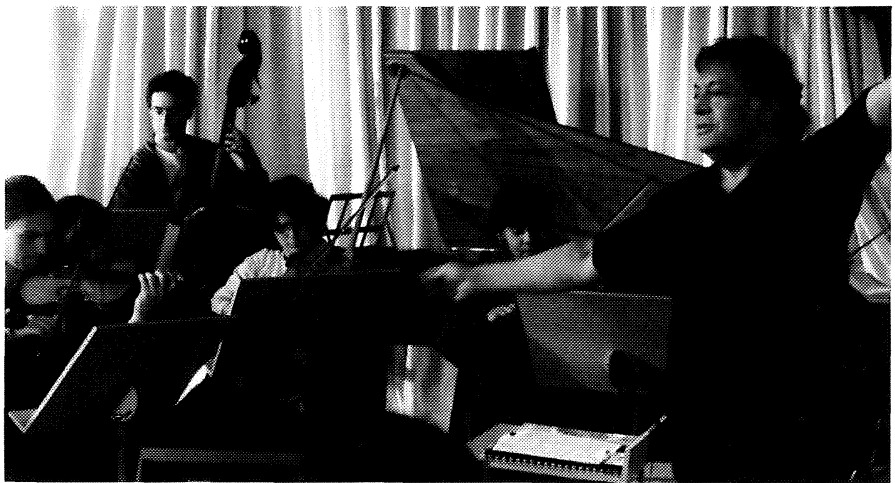

Zubin Mehta ensaya con la Orquesta de Cámara de la Escuela.

empresariales. Invertir en cultura, si se hace bien, puede resultar rentable a corto, a medio y a largo plazo, y la experiencia de la Fundación Albéniz es una buena prueba de ello.

$\mathrm{Al}$ carecer de patrimonio económico, la Fundación ha tenido que prestar especial atención a la diversificación del riesgo. Para ello se diseñó un sistema por el cual cada programa tendría plena autonomía financiera. Un programa sólo se ejecutaría cuando se hubieran conseguido los fondos suficientes y se desarrollaría en las estrictas coordenadas de lo presupuestado. Los programas así establecidos concluyen al satisfacer los objetivos previstos.

Tengo que reconocer, y lo hago encantada, que son muchas las empresas que se han ido integrando como «compañeros de viaje» de nuestro proyecto durante estos años. Veo con ilusión que en nuestro país, en nuestra sociedad, comienza a extenderse cada vez más un espíritu positivo de hacer cosas para los demás, un fenómeno nuevo que tiene importantes implicaciones en las tareas de mecenazgo. Siempre he creído que tanto la cultura como la empresa se necesitan de manera complementaria, y que una no puede desarrollarse si no lo hace la otra. El mecenazgo 
tiene una importancia capital en nuestra sociedad, ya que gracias a él, a los nuevos mecenas, se ha avanzado considerablemente en campos como la cultura, el deporte, la ciencia o la tecnología.

La financiación del nuevo edificio, la amplia oferta de programas de la Fundación, el Concurso de Piano de Santander, las diferentes cátedras académicas de la Escuela, los grupos de cámara, la orquesta, las becas de matrícula y residencia, los cursos de verano, etc., todo se convierte en producto desde la perspectiva de los que deseen invertir en este proyecto educativo. Independientemente del prestigio que otorga a una empresa el hecho de ver su nombre asociado a cualquiera de los programas que ofrece la Fundación, su colaboración es, sin lugar a dudas, reflejo de la sensibilidad individual y empresarial hacia una tarea bien hecha y de vital importancia en cualquier sociedad moderna.

Este esfuerzo privado se complementa con la ayuda que nos ofrecen desde hace años las Instituciones Públicas. Ellas son también «culpables» de que este proyecto de educación musical crezca día a día con más fuerza. El Estado ha asumido con ejemplaridad su deber con el fomento de la cultura y ha firmado con la Fundación importantes acuerdos que permiten trabajar con la estabilidad y la garantía de continuidad necesarias.

\section{El futuro...}

En esencia, esto es la Fundación Albéniz; una empresa cultural comprometida con la modernización musical española que vive del mecenazgo privado y de la colaboración pública. Una empresa que también tiene que demostrar, día a día, la utilidad social de sus programas.

Aunque nuestra obra es pionera en España, debe mucho a experiencias anteriores, sobre todo a las que se han desarrollado en los últimos años en el mundo anglosajón. Desde luego, no tenemos ningún ánimo de exclusividad. Más bien, todo lo contrario. Si nuestra experiencia puede ser útil para nuevas empresas culturales, será para nosotros una enorme satisfacción. A estas alturas de la historia resulta una frivolidad y una equivocación pensar que el Estado puede hacerse cargo de todas las responsabilidades sociales. Es la propia sociedad la que debe asumir buena parte de ellas, no para competir con el Estado sino para complementar su labor. Por eso, si en los próximos años no siguieran apareciendo nuevas instituciones realmente ejecutivas, la modernización de nuestras estructuras culturales sería muy difícil.

En Europa todavía nos queda un largo camino para llegar al nivel de profesionalización que tienen las llamadas instituciones del tercer sector 
La música por excelencia. La Fundación Albéniz: una...

en Estados Unidos. Pero también es un hecho cierto que los europeos estamos exigiendo cada vez más a nuestras fundaciones y que el futuro se presenta prometedor. Yo espero que el camino que vayamos a recorrer en los próximos años pase inevitablemente por un trabajo en asociación, por una colaboración entre fundaciones, en definitiva, por un nuevo concepto de madurez empresarial. Lo que nos jugamos es el mejor modo de servir a la sociedad, a nosotros mismos, a nuestros hijos, a las nuevas generaciones.

Ésa es la meta principal, la que debe orientar nuestros pasos, la que explica que la vinculación de nuestras empresas con el desarrollo de nuestra cultura sea un signo característico de las sociedades avanzadas. Y para ello, las asociaciones de intereses a las que acabo de referirme no pueden implicar sólo la cofinanciación de determinadas tareas, sino, por encima de todo, un modo de pensar compartido. Una misma ilusión y una misma responsabilidad de todos para trabajar por una sociedad más dinámica, más culta y más solidaria. 